\title{
A governança no contexto da pesquisa em educação no Brasil
}

\author{
Aline Veiga dos santos \\ Isabela Cristina Marins Braga \\ Ranilce Mascarenhas Guimarães-losif \\ Universidade Católica de Brasília
}

Resumo: O artigo analisa a emergência da "governança" na literatura internacional e nacional e seu uso nas pesquisas em educação no Brasil. Trata-se de um estudo analítico-descritivo das produções sobre a governança educacional cadastradas nas bases Scientific Electronic Library Online e Biblioteca Digital Brasileira de Teses e Dissertações no período de 2004 a 2015. Apesar de ser um campo de estudos incipiente, as pesquisas sobre o tema revelam-se fundamentais para a compreensão das mudanças ocorridas no papel do Estado na gestão de suas políticas a partir da década de 1990. Essa abordagem permite uma análise não linear das redes que compõem o complexo campo das políticas de educação.

Palavras-chave: Governança. Governança educacional. Pesquisa em Educação. Política Educacional. Redes. 


\section{Governance in the context of educational research in Brazil}

The article analyzes the emergence of "governance" in international and national literature and its use in educational research in Brazil. It is an analytical-descriptive study of papers on educational governance found in the databases of the Scientific Electronic Library and Brazilian Digital Library of Theses and Dissertations, from 2004 to 2015. Despite representing an emerging field, research into the subject is fundamental for understanding the changes in the state's role in managing its policies from the 1990s This approach allows a non linear analysis of the networks that make up the complex field of education policies.

Keywords: Governance. Educational governance. Research in Education. Educational policy. Networks.

\section{Gobernación en el contexto de la investigación educativa en Brasil}

El artículo analiza la emergencia de la "gobernación" en la literatura internacional y nacional, y su uso en las investigaciones educativas en Brasil. Es un estudio analitico-desciptivo de las producciones sobre la gobernación educativa registrada en las bases Scientific Electronic Library On line y Biblioteca Digital Brasileña de Tesis y Disertaciones en el periodo de 2004 hasta 2015. Aunque sea un campo de estudios incipiente, las investigaciones sobre el tema demuestra fundamental para entender los cambios en el papel del Estado en la gestión de sus políticos desde de la década de 1990. Ese abordaje permite un análisis no linear de las redes que forma parte en el complejo campo de las políticas educativas.

Palabras-clave: Gobernación. Gobernación educativa. Investigación en Educación. Política Educativa. Rede. 


\section{La gouvernance dans le contexte de la recherche en éducation au Brésil}

Cet article analyse l'émergence de la "gouvernance" dans la littérature internationale et nationale et son utilisation dans la recherche en éducation au Brésil. C'est une étudeanalytique-descriptive d'articles sur la gouvernance éducative détectés dans la Bibliothèque électronique scientifique et Bibliothèque numérique brésilienne de thèses et dissertations, de 2004 à 2015. Quoique cette recherche représente un champ en émergence, elle est cruciale pour mieux comprendre les changements du rôle de l'État dans la gestion des politiques publiques, au Brésil, dans les années 1990, et aussi, une analyse non linéaire des réseaux qui composent le domaine complexe des politiques d'éducation.

Mots-clés: Gouvernance. Gouvernance éducative. Recherche en éducation. Politique éducative. Réseaux. 


\section{Introdução}

Em um cenário marcado pelas metamorfoses no papel do estado e pela emergência de novas formas de perpetrar e pensar a política e a gestão pública, o termo governance (governança ou governação) ganha notoriedade em pesquisas de áreas distintas e aos poucos se difunde na educação. No Brasil, o número de pesquisas e artigos que abordam o tema cresceu nos últimos anos, mas ainda é bastante restrito, situando-se mais especificamente no campo de estudos voltados para a análise das políticas ou da gestão educacional.

No intuito de contribuir com a discussão do tema e ampliar a produção em língua portuguesa nessa área de conhecimento em expansão significativa no contexto internacional, este artigo discute os principais conceitos de governança na literatura especializada e traz a discussão para o uso da governança educacional na pesquisa em educação no Brasil. Trata-se de estudo analítico-descritivo que examina pesquisas da área de educação sobre governança à luz da análise de conteúdo (Bardin, 2010). Foi realizado um levantamento das produções registradas nas bases de dados Scientific Electronic Library Online (SciELO) e Biblioteca Digital Brasileira de Teses e Dissertações (BDTD). Elegeram-se os trabalhos dessas bases eletrônicas visto que elas são referências nacionais. Adota-se, como referência temporal, o espaço de uma década (2004-2015), tendo em vista que o número de pesquisas na área de educação acerca do tema, no país, ainda são incipientes.

\section{Governança: gênese e polissemia do conceito}

As raízes teóricas da governança são múltiplas - economia institucional, relações internacionais, estudos organizacionais, estudos de desenvolvimento, ciência política, administração pública e inspirações teóricas foucaultianas. Os trabalhos precursores assentam no corporativismo, na comunidade política e na gama de análises econômicas interessadas na evolução dos sistemas econômicos (Stoker, 1998). Em 1937, conforme Reis (2013), Ronald Coase foi o primeiro estudioso artigo intitulado The nature of the firm - a se referir ao termo governança, a intento dos dispositivos tomados pelas empresas para reduzir os custos de transação, resultantes da coordenação econômica. Em 1975, depois de quase quatro décadas, o termo se formaliza com o trabalho do economista americano Oliver Eaton Williamson - Markets and Hierarchies: Analysis and Antitrust Implications. Desde então, o conceito de governança propagou-se, mas também se diferenciou. $O$ seu significado é amplo, "na medida em que se refere à análise dos padrões de articulação e cooperação entre os atores e os arranjos institucionais que coordenam 
os sistemas sociais" (Reis, 2013, p. 104).

Até 1975, a biblioteca do Museu Britânico havia catalogado 47 títulos contendo a palavra governance. Desde então, o termo apresentou uma propagação célere em todas as disciplinas das ciências sociais. Essa proliferação vertiginosa só encontra paralelo, no período em tela, no termo globalização. Em meados da década de 1990, a governança se tornou o mote político da globalização neoliberal (Santos, 2010). Segundo Lima (2007), as novas formas de fazer política inspiraram-se em conceitos como "menos estado, melhor estado" e promoveram processos de privatização, desregulação estatal e descentralização. Essa nova dinâmica e a consequente perda de legitimidade estatal alcançou o seu ponto mais alto nos governos de Margareth Thatcher (Reino Unido) e Ronald Reagan (EUA). Movidos pela ideologia nomeada "nova direita", que almejava a diminuição do Estado em favor do setor privado, a introdução de uma filosofia empresarial na gestão dos assuntos públicos e a redução de custos e o funcionamento mais eficaz do governo. Essa ideologia se propagou em diversas conjunturas nacionais e em escalas transnacionais." Com estes desenvolvimentos, tornaram-se evidentes as interdependências entre os governos e inúmeros atores sociais e ganhou crescente relevo o conceito de governança" (Lima, 2007, p. 165).

Na América Latina, esses preceitos se aprofundam por meio do Consenso de Washington (1989), considerado o apogeu do neoliberalismo. Santos (2012) destaca que a globalização neoliberal, pós Consenso de Washington, propagou o atual modelo de gestão pública, denominado governança. O documento defendia um conjunto de reformas, tais como: concentração de gastos públicos em atividades prioritárias (educação, saúde, infraestrutura), reforma tributária, liberalização financeira, eliminação das restrições legais à entrada de capitais estrangeiros, privatização das empresas estatais, desregulamentação do trabalho e da legislação, entre outras.

Dale (2006, p. 66) ressalta que "quando o Consenso de Washington pareceu não proporcionar o que se pretendia, provavelmente devido à sua dureza, o Banco Mundial apareceu com uma abordagem alternativa, desta vez baseada em 'boa governança". Emerge então a concepção de "governança pública", que ganha destaque nos documentos Governance and Development (World Bank, 1992) e Governance in Transition (OECD, 1995). Nessa perspectiva, a governança é "a maneira pela qual o poder é exercido na administração dos recursos econômicos e sociais do país, com vistas ao desenvolvimento" (World Bank, 1992, p. 1). O Banco Mundial recomenda um modelo de boa governança fundado em quatro princípios: gestão pública baseada no princípio da eficiência, estrutura legal, accountability e transparência. O objetivo é criar um novo caminho para o desenvolvimento mundial por meio das reformas governamentais e da instrumentalidade dos serviços. "A partir daí, surgiram vários estudos acadêmicos que buscaram, e ainda procuram, compreender melhor essa 
nova terminologia que passou a integrar também o dicionário educacional em todo o mundo" (Guimarães-losif, 2012, p. 17).

No Brasil, no contexto pós-constituinte (1988), o conceito de governança desponta na discussão sobre o papel do Estado. A nova governança pública se materializa por meio da Reforma Administrativa, direcionada à capacidade gerencial do Estado, que visa à eficiência na oferta de serviços aos cidadãos. O Plano Diretor de Reforma do Aparelho do Estado (Brasil, 1995) foi orquestrado no governo do presidente Fernando Henrique Cardoso (1995-2002), sob a gestão do ministro da administração, Luiz Carlos Bresser Pereira, e, no caso da educação, mais especificamente, pelo ministro Paulo Renato de Souza (Tavares, 2009). É a partir da reforma do Estado brasileiro que os pesquisadores passam a estudar a temática (Hoyler et al., 2014).

A tese de Jessop é a de que a governança desponta no bojo da mudança do Estado de bem-estar social. O período fordista concebeu um conjunto extenso de estruturas hierárquicas cujo modelo ampliou os papéis econômicos e sociais do Estado. Esse modelo está sendo desafiado pelo novo paradigma de rede, que destaca a autorregulação, a auto-organização e o contexto de descentralização do governo. Esse processo abrange a modificação tendencial de um "imperativo de coordenação pelo Estado soberano para uma ênfase na interdependência, nas divisões do conhecimento, na negociação reflexiva, na mútua aprendizagem. Em suma, há uma mudança de governo para governança" (Jessop, 1999, p. 354-355, grifos do autor).

$\mathrm{Na}$ contemporaneidade, a governança passou a se referir também às formas de organização da sociedade civil e à ação pública. Cientistas sociais, notadamente os que pesquisam o setor público e o governo local, argumentam que a organização e a ação pública deslocaram-se "da hierarquia e da burocracia para os mercados e as redes" (Bevir, 2011, p. 103). A governança emerge a partir de duas arenas distintas da reforma do setor público:

A primeira consistiu nas reformas associadas ao conceito econômico de racionalidade - o neoliberalismo, a Nova Administração Pública [New Public Management] e a terceirização. A segunda consistiu em reformas associadas a conceitos sociológicos de racionalidade - a Terceira Via, a governança joined-up e redes e parcerias (Bevir, 2011, p. 107, grifos do autor).

A governança constitui uma mudança no significado de governo, referindo-se ao novo processo de governar, às mudanças nas condições das regras estabelecidas, ou seja, ao novo método pelo qual a sociedade se organiza e é governada (Rhodes, 1996). A mudança de governo para governança (Rhodes, 1996; Jessop, 1999; 2013; 
Rosenau, 2000; Dale, 2010; Ball, 2013) denota que formas tradicionais de intervenção passaram a ter menos importância na atual política econômico-social, "com exceção dos momentos de crise e emergências, quando se espera que o Estado atue como um recurso de última instância, mobilizando seus meios de intervenção convencionais ou inventando outros novos meios" (Jessop, 2013, p. 272-273).

Há duas décadas, Rhodes (1996) já identificava seis usos distintos do termo governança na literatura referente ao tema: estado mínimo, governança corporativa, nova gestão pública, boa governança, sistemas sócio-cibernéticos, e redes de autoorganização. Na visão do autor, a governança refere-se à auto-organização das redes interorganizacionais. Essas redes complementam mercados e hierarquias, bem como regem estruturas para alocar recursos com autoridade e exercer controle e coordenação. A ideia de redes interconectadas com o conceito de governança também é reforçada por Stoker (1998), Jessop (1999; 2013), Lima (2007), Bevir (2011) e Ball (2013). Redes de governança abrangem não apenas a influência política no governo, mas assumem as negociações com o governo (Stoker, 1998). Assim, a governança é compreendida como "a gestão pública de complexas redes interorganizacionais que se substituem às unidades tradicionais do Estado na oferta de serviços públicos à população e que cruzam frequentemente as fronteiras dos setores público, privado e cooperativo", corrobora Lima (2007, p. 167). O atual cenário político do Brasil coloca em evidência esse novo modelo de governar e de gerir as políticas públicas, sejam elas da educação ou de qualquer outra área econômica ou social.

A despeito dos diferentes usos e emprego em diferentes áreas, Rhodes (1996) destaca algumas características comuns da governança, tais como: a) interdependência entre organizações (a alteração das fronteiras do Estado significa que as fronteiras entre os setores público,privado e voluntário tornaram-se incertas e difusas); b) interações contínuas entre os atores da rede motivadas pela necessidade da troca de recursos e da negociação de propósitos compartilhados; c) as interações em jogo estão enraizadas na confiança e reguladas por regras negociadas e acordadas pelos participantes da rede; d) há um grau significativo de autonomia em relação ao Estado.

Nesse contexto, a governança versa sobre a tentativa de gerenciar, por cursos governamentais e não-governamentais, uma globalização que se estende a todos os setores do sistema mundo. Santos (2010, p. 407) pontua que em momento algum o Estado não se ausenta nessa dinâmica. A passagem da legitimidade à governabilidade foi suscitada pela fragilidade do Estado enquanto regulador social. Contudo, o Estado não está desprovido de seu papel de "meta-regulador", isto é, de ente responsável por gerar espaços para reguladores não-estatais legítimos. Os movimentos sociais, globalmente organizados nas últimas décadas, também ganharam força como atores contra-hegemônicos do modelo dominante de governança, que limita direitos sociais 
e reforça raízes colonizadoras (Santos, 2010) que se renovam por meio de acordos políticos e econômicos, tanto na esfera nacional como inter e transnacional.

As concepções da governança prosseguem amplamente semeadas, debatidas e experimentadas e, apesar de trazer elementos conceituais contraditórios, são cada vez mais difundidas na literatura das mais diversas área de conhecimento: administração, direito, sociologia, economia, tecnologia, educação. Apesar de seu crescimento em uma escala global, o processo ainda permanece introvertido na pesquisa em educação no Brasil. Todavia, o levantamento da produção acadêmica aponta avanços consideráveis nos últimos cinco anos.

\section{Governança educacional}

A governança passou a receber atenção redobrada na educação desde que foram trazidos à tona pela primeira vez, sob o nome de nova administração pública, com maior impulso, na década de 1980. No Brasil, os conceitos e práticas de governança adentraram aos poucos no ambiente educacional e ganharam destaque a partir da Constituição Federal (Brasil, 1988), da Reforma do Estado (Brasil, 1995) e da promulgação da Lei de Diretrizes e Bases da Educação Nacional - LDBEN (Brasil, 1996).

Com a retomada da democracia após duros 20 anos ditatoriais, a Constituição Federal (BRASIL, 1988) assegurou a liberdade de ensino à iniciativa privada (art. 209) e a organização dos sistemas de ensino em regime de colaboração (art. 211). Seguindo os passos da CF de 1988, a LDBEN, dentre outras medidas que fortalecem o crescimento do setor privado na oferta da educação no Brasil, estabelece que:

Art. 7 O ensino é livre à iniciativa privada, atendidas as seguintes condições: Icumprimento das normas gerais de educação nacional e do respectivo sistema de ensino; II- autorização de funcionamento e avaliação da qualidade pelo poder público; III- capacidade de autofinanciamento, ressalvado o previsto no art. 213 da Constituição Federal. [...]

Art. 16 O sistema federal de ensino compreende: as instituições de ensino mantidas pela União, como os centros federais de educação tecnológica e as universidade federais, as instituições de educação superior criadas e mantidas pela iniciativa privada e os órgãos federais de educação como o Conselho Nacional de Educação (CNE) e o Instituto Nacional de Estudos Pedagógicos (INEP). (BRASIL, 1996). 
O art. 19 classificou as IES em duas categorias: públicas, criadas e mantidas pelo poder público; e privadas, mantidas e gerenciadas por pessoas físicas ou jurídicas de direito privado. $\mathrm{O}$ art. 20 enquadrou as instituições privadas em três tipos: particulares, em sentido estrito, com fins lucrativos; comunitárias, sem fins lucrativos, que incluam na entidade mantenedora representantes da comunidade; e confessionais e filantrópicas, sem fins lucrativos. $O$ art. 80 contemplou a educação a distância (EAD) em todos os níveis e modalidades de ensino e de educação continuada (BRASIL, 1996).

A LDBEN fomentou a criação de uma diversidade de instituições e cursos de nível superior, além de consentir que as entidades mantenedoras das IES adquirissem a forma de sociedade mercantil, isto é, de pessoas jurídicas de direito privado com fins lucrativos e contribuiu para a expansão das instituições educacionais com fins lucrativos. Na prática isso tem promovido o processo corrente de fusões e aquisições, bem como a abertura de capital na bolsa de valores e a inserção de capital internacional nessas instituições. Diante desta nova realidade, as mantenedoras das instituições de ensino, visando à consolidação no mercado, passaram a adotar diferentes modelos de governança (ver Tavares, 2011), que impactaram diretamente na gestão das instituições (Santos, 2012).

Essas medidas abriram espaço para o surgimento de novos atores e instituições que passaram a interferir direta ou indiretamente no modo de se pensar, gerir e financiar as políticas de educação no País. A emergência das grandes consultorias e dos conglomerados educacionais nacionais e internacionais voltados para a oferta ou avaliação do setor educacional amplia sobremaneira a rede de governança da educação básica e superior brasileira.

Caracterizados por processos complexos e inter-relações que envolvem uma gama de atores, instituições, conhecimentos e valores, os estudos sobre governança despontam no cenário internacional como elementos fundantes para a compreensão não linear das políticas educacionais. A governança da educação tem uma natureza multiescalar (Dale, 2010) e evidencia que as políticas educacionais não se caracterizam mais como reserva exclusiva dos Estados-Nação.

No campo da pesquisa em política, gestão e financiamento da educação, a governança se tornou um termo importante devido às profundas modificações na área e às suas relações com outras áreas do conhecimento, tais como: economia, administração, ciências políticas, tecnologia e sociologia da educação. Essas mudanças envolvem os instrumentos e os meios de direcionamento, os novos modos de ofertar e organizar os serviços educacionais e a inclusão de novos atores nos diversos contextos da política educacional (Amos, 2010). Hoyler et al. (2014) ressaltam que o estabelecimento de um quadro conceitual de governança no âmbito educacional favorece a compreensão 
do complexo modus operandi das políticas públicas e das relações que se formam entre poder público e demais atores na arena de disputa de interesses e recursos.

No Brasil e no mundo, a governança se difunde junto com os ideais da globalização neoliberal e se estabelece como uma panaceia para os males da gestão pública e privada de instituições educacionais em contextos locais e globais. Originalmente, os estudos sobre governança provém da ciência política e das ciências sociais, conceito que emerge junto com o desafio de compreender a nova configuração do Estado e sua articulação com diversos atores nacionais e transnacionais.

A governança educacional surge com a promessa de ajudar os gestores e empresários da educação a encontrar respostas mais eficientes e eficazes para os desafios da redução de custos e do fortalecimento de parcerias ao se democratizar o acesso tanto na educação básica quanto superior. Diante do imbricado contexto das políticas de educação no Brasil, em que se verifica uma mudança substancial no papel do Estado e um aumento significativo das parcerias público-privadas, a análise das políticas educacionais a partir da lente de suas redes de governança torna-se fundamental. Nesse sentido, é preciso ampliar a pesquisa e a compreensão sobre o assunto.

\section{A governança nas pesquisas em educação no Brasil}

Com o intuito de identificar e analisar as produções acadêmicas sobre o tema "governança da educação", esse artigo problematiza o tema a partir de um levantamento realizado nas bases de dados SciELO e BDTD, adotando como referência o espaço temporal de uma década (2004-2015). O levantamento baseou-se nos seguintes descritores: governança, governança da educação e governança educacional. Os resultados foram organizados a partir do mapeamento dos trabalhos analisados e contemplam o ano de publicação, a unidade federativa, a instituição na qual o trabalho está vinculado e a área de conhecimento. No sentido de compreender também os delineamentos teóricos e metodológicos da produção em tela, optou-se pela análise de conteúdo (Bardin, 2010) para examinar os artigos e as dissertações e teses.

A pesquisa realizada na base de dados SciELO, registrou a existência de 358 trabalhos, com maior concentração nas áreas de conhecimento de administração (124 trabalhos), sociologia (33 trabalhos), economia (27 trabalhos), ciências contábeis (24 trabalhos) e ciências políticas (19 trabalhos). Desse modo, obteve-se um total de 227 estudos sobre governança no período de uma década, dentro da grande área das ciências sociais. Na área de conhecimento educação, foram encontrados 7 artigos. A produção 
acadêmica acerca da governança da educação no Brasil revelou que se trata de uma temática atual, mas ainda pouco discutida na academia nacional, passando a ser mais pesquisada a partir do ano de 2010. Apesar dos dados assinalarem que o tema segue pouco problematizado no campo das pesquisas em educação, torna-se fundamental proporcionar maior visibilidade ao assunto, tendo em vista sua importância para a análise do contexto das políticas educacionais. O Quadro abaixo apresenta uma descrição sucinta dos trabalhos encontrados.

Quadro 1: Produção sobre governança educacional na base SciELO no período de 2004-2015

\begin{tabular}{|c|c|c|c|c|}
\hline$\frac{\text { Ano }}{20004}$ & 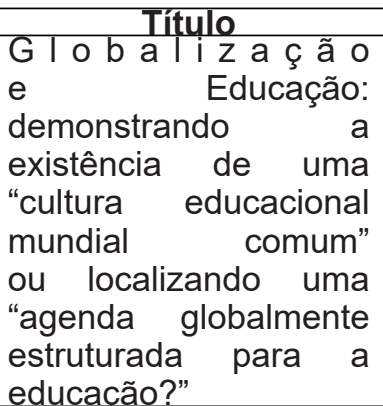 & $\begin{array}{l}\text { Palavras-chave } \\
\text { Globalização e educação. } \\
\text { Cultura universal da } \\
\text { educação. } \quad \text { Estado } \\
\text { nacional e educação. }\end{array}$ & $\begin{array}{c}\text { Autor } \\
\text { Roger Dale }\end{array}$ & $\begin{array}{l}\text { Revista } \\
\text { Educaçăo \& } \\
\text { Sociedade }\end{array}$ \\
\hline 2010 & $\begin{array}{l}\text { A Sociologia da } \\
\text { Educação e o Estado } \\
\text { após a globalização }\end{array}$ & $\begin{array}{l}\text { Estado. Problemas } \\
\text { centrais do capitalismo. } \\
\text { Políticas educacionais. } \\
\text { Governança educacional. } \\
\mathrm{N} \text { a c i o n a I i s m o } \\
\text { metodológico. }\end{array}$ & Roger Dale & $\begin{array}{l}\text { Educação \& } \\
\text { Sociedade }\end{array}$ \\
\hline 2010 & $\begin{array}{l}\text { Governança } \\
\text { governamentalidade: } \\
\text { relação e relevância } \\
\text { de dois conceitos } \\
\text { científico-sociais } \\
\text { proeminentes na na } \\
\text { educacão comparada }\end{array}$ & $\begin{array}{l}\text { Go v e r n a n c a } \\
\text { Governamentalidade. } \\
\text { Política educacional. } \\
\text { Foucault. Governança } \\
\text { educacional. }\end{array}$ & Karir & $\begin{array}{c}\text { Educação e } \\
\text { Pesquisa }\end{array}$ \\
\hline 2012 & $\begin{array}{l}\text { A origém das parcerias } \\
\text { público-privadas na } \\
\text { governança global da } \\
\text { educação }\end{array}$ & $\begin{array}{l}\text { Parcerias público- } \\
\text { privadas. Globalização. } \\
\text { Governança educacional. } \\
\text { Empreendedores de } \\
\text { nolíticas }\end{array}$ & $\begin{array}{l}\text { Susan } \\
\text { Robertson } \\
\text { e Antoni } \\
\text { Verger }\end{array}$ & $\begin{array}{l}\text { Educação \& } \\
\text { Sociedade }\end{array}$ \\
\hline 2012 & Gerencialismo & $\begin{array}{lr}\text { Gerencialismo. } & \text { Estado. } \\
\text { Autoridade. } & \text { Poder. } \\
\text { Austeridade. } & \\
\end{array}$ & $\begin{array}{c}\text { Janet } \\
\text { Newman e } \\
\text { John Clarke }\end{array}$ & $\begin{array}{c}\text { Educaçãoo } \\
\text { Real }\end{array}$ \\
\hline 2013 & $\begin{array}{lr}\text { As implicações } & \text { em } \\
\text { justiça social da } & \text { da } \\
\text { privatização ros } \\
\text { modelos de governança } \\
\text { da educação: um relato } \\
\text { relacional }\end{array}$ & $\begin{array}{lr}\text { Justiça } & \text { Social. } \\
\text { Educação. } & \text { Modelos de } \\
\text { governança educacional. } \\
\text { Globalização. } \\
\text { relacional. }\end{array}$ & $\begin{array}{l}\text { Susan } \\
\text { Robertson }\end{array}$ & $\begin{array}{l}\text { Educação \& } \\
\text { Sociedade }\end{array}$ \\
\hline
\end{tabular}




\begin{tabular}{|l|l|l|c|c|}
\hline 2014 & $\begin{array}{l}\text { Um esboço crítico sobre } \\
\text { "parceria" na formação } \\
\text { de professores }\end{array}$ & $\begin{array}{l}\text { Análise de Discurso } \\
\text { Crítica. Sistema posição- } \\
\text { prática. Formação de } \\
\text { professores. Programa } \\
\text { Institucional de Bolsa de } \\
\text { Iniciação à Docência }\end{array}$ & $\begin{array}{c}\text { Elaine } \\
\text { Fernandes } \\
\text { Mateus }\end{array}$ & $\begin{array}{c}\text { Educação } \\
\text { em Revista }\end{array}$ \\
\hline
\end{tabular}

Fonte: Elaboração das autoras.

As publicações na base SciELO acerca da governança educacional são recentes. Somente um estudo foi publicado no ano de 2004. Os demais se concentram principalmente nos anos de 2010 e 2012 (2 artigos em cada ano), 2013 e 2014 (um em cada ano). Quanto às palavras-chave, o destaque recai nos termos governança, governança educacional, políticas educacionais, globalização e Estado.

No tocante à localização geográfica, a região Sudeste concentra o maior número de publicações (6) e a região Sul, uma. O estado de São Paulo abrigou o maior número de trabalhos, registrando 2 revistas que são consideradas referências na área - Educação \& Sociedade e Educação e Pesquisa. O destaque dos periódicos fica a cargo da revista: Educação \& Sociedade, do Centro de Estudos Educação e Sociedade da Unicamp, com 4 artigos publicados. Nas demais revistas - Educação Real, Educação em Revista e Educação e Pesquisa -, foi encontrado apenas um artigo em cada.

A pesquisa na base SciELO evidenciou que a produção acadêmica sobre o assunto é predominantemente internacional. Apesar de serem estudos publicados em revistas nacionais, a maioria dos autores são estrangeiros e estão vinculados às universidades do Reino Unido (Dale, 2004; 2010; Newman; Clarke, 2012; Robertson; Verger, 2012; Robertson, 2013) e da Alemanha (Amos, 2010). Há somente um trabalho de autoria brasileira (Mateus, 2014).

O levantamento realizado na base BDTD confirma o quanto a pesquisa sobre governança educacional ainda é incipiente no Brasil, cuja produção começa a despontar em 2012. No total, foram identificadas 8 dissertações e 5 teses da área de Educação que tratam do assunto. A região de maior representatividade dessa produção é a Sudeste com 6 pesquisas, seguida da Centro-Oeste com 5 e da Sul com 2. Assim como na base SciELO, nas regiões Norte e Nordeste, não foi encontrada nenhuma pesquisa. O Quadro abaixo ilustra esses dados. 
Quadro 2: Produção sobre governança educacional na base BDTD no período de 2004-2015

\begin{tabular}{|c|c|c|c|c|c|}
\hline ANO & Título & Palavras-chave & $\begin{array}{l}\text { Tipo de } \\
\text { Trabalho }\end{array}$ & Autor & TES \\
\hline 2012 & $\begin{array}{l}\text { A governança } \\
\text { da educação } \\
\text { superior privada: } \\
\text { sobreimplicações da } \\
\text { formação dos oligopólios } \\
\text { no trabalho docente }\end{array}$ & $\begin{array}{l}\text { Governança. } \\
\text { Educação Superior } \\
\text { Privada. Formação } \\
\text { dos Oligopólios. } \\
\text { Trabalho Docente. }\end{array}$ & Dissertação & $\begin{array}{l}\text { Aline Veiga } \\
\text { dos Santos }\end{array}$ & UCB \\
\hline 2012 & $\begin{array}{l}\text { Ouvidoria da educação: } \\
\text { a construção de espaços } \\
\text { de mediação de conflitos } \\
\text { no cotidiano escolar de } \\
\text { Nova lquacu }\end{array}$ & $\begin{array}{l}\text { Ouvidoria da } \\
\text { Educação. Gestão } \\
\text { Democrática. } \\
\text { Educação Integral }\end{array}$ & Dissertação & $\begin{array}{l}\text { Sonia de } \\
\text { P o n t e s } \\
\text { Leandro }\end{array}$ & UERJ \\
\hline 2013 & $\begin{array}{l}\text { educaçã̃o inclusiva ou } \\
\text { contribuições da teoria } \\
\text { histórico-cultural para } \\
\text { uma análise crítica da } \\
\text { realidade escolar }\end{array}$ & $\begin{array}{l}\text { Educação. } \\
\text { Educação } \\
\text { inclusiva. Políticas } \\
\text { de estado }\end{array}$ & Dissertação & $\begin{array}{l}\text { Sandra Paula } \\
\text { da Silva } \\
\text { Batistão }\end{array}$ & USP \\
\hline 2013 & $\begin{array}{l}\text { O trabalhador } \\
\text { da educação e a } \\
\text { acumulação flexível } \\
\text { do capital: um estudo } \\
\text { do posicionamento do } \\
\text { Sintego frente à política } \\
\text { educacional de Goiás }\end{array}$ & $\begin{array}{l}\text { Sintego. } \\
\text { Acumulação } \\
\text { flexível. } \\
\text { Pacto pela } \\
\text { Educação. } \\
\text { Trabalho } \\
\text { Pedaaóaico }\end{array}$ & Dissertação & $\begin{array}{l}\text { João } \\
\text { derreira } \\
\text { Júnior }\end{array}$ & UFG \\
\hline 2013 & $\begin{array}{l}\text { Reconfiguração da } \\
\text { gestão da educação: } \\
\text { um estudo de caso na } \\
\text { segunda Coordenadoria } \\
\text { Regional de Educação } \\
\text { de São Leopoldo/RS }\end{array}$ & $\begin{array}{l}\text { Educação. Rio } \\
\text { Grande do Sul. } \\
\text { Escolas Públicas. } \\
\text { Administração } \\
\text { Educacional. } \\
\text { Políticas Públicas }\end{array}$ & Tese & Taís Schmitz & UCRS \\
\hline 2013 & $\begin{array}{l}\text { educação infantil: } \\
\text { a participação de } \\
\text { atores não estatais na } \\
\text { elaboração da política } \\
\text { pública }\end{array}$ & $\begin{array}{l}\text { Políticas públicas. } \\
\text { Educação infantil. } \\
\text { Educação de } \\
\text { crianças. Política } \\
\text { educacional }\end{array}$ & Tese & $\begin{array}{l}\text { Tsabel C. A. } \\
\text { Lima e Silva }\end{array}$ & UEC \\
\hline 2013 & $\begin{array}{l}\text { Olnstituto Federal de } \\
\text { Educação, Ciência e } \\
\text { Tecnologia (Instituto } \\
\text { Federal) como nova } \\
\text { institucionalidade na } \\
\text { Educação Profissional e } \\
\text { Tecnológica (EPT): uma } \\
\text { análise na perspectiva de } \\
\text { rede de política pública }\end{array}$ & $\begin{array}{l}\text { Institucionalidade. } \\
\text { Policy networks. } \\
\text { Governança. } \\
\text { Instituto Federal }\end{array}$ & Dissertação & $\begin{array}{lr}\text { Maria da } \\
\text { Glória dos } \\
\text { Santos Laia }\end{array}$ & UNB \\
\hline
\end{tabular}




\begin{tabular}{|c|c|c|c|c|c|}
\hline 2014 & $\begin{array}{l}\text { A reforma educacional } \\
\text { chilena na América } \\
\text { Latina (1990-2000): } \\
\text { circulação e regulação } \\
\text { de políticas através do } \\
\text { conhecimento }\end{array}$ & $\begin{array}{l}\text { Política } \\
\text { educacional. } \\
\text { Relações } \\
\text { internacionais }\end{array}$ & Tese & $\begin{array}{l}\text { Jorge Luis } \\
\text { I } n \text { z u n z a } \\
\text { Higueras }\end{array}$ & UEC \\
\hline 2014 & $\begin{array}{l}\text { A pessoa do gestor } \\
\text { e do educador leigo } \\
\text { como estimuladores } \\
\text { da proposta educativa } \\
\text { Marista no RS: do } \\
\text { empenho original do } \\
\text { fundador, Marcelino } \\
\text { Champagnat, aos } \\
\text { desafios do século XXI }\end{array}$ & $\begin{array}{l}\text { Administração } \\
\text { Educacional. } \\
\text { Educação Marista. } \\
\text { Educadores. }\end{array}$ & Dissertação & $\begin{array}{l}\text { Adelmo } \\
\text { Germano } \\
\text { Etges }\end{array}$ & UCRS \\
\hline 2014 & $\begin{array}{l}\text { A instituição da agenda } \\
\text { contratual na educação } \\
\text { mineira: arquitetura de } \\
\text { uma reforma }\end{array}$ & $\begin{array}{l}\text { Contratualismo. } \\
\text { Educação básica. } \\
\text { Políticas } \\
\text { educacionais. } \\
\text { Reforma gerencial }\end{array}$ & Tese & $\begin{array}{l}\text { Maria do } \\
\text { Rosário F. } \\
\text { Tripodi }\end{array}$ & USP \\
\hline 2014 & $\begin{array}{l}\text { Plano Nacional de } \\
\text { Educação - PNE 2001- } \\
\text { 2010: análise de fatores } \\
\text { que influenciaram sua } \\
\text { implementação no } \\
\text { âmbito da união }\end{array}$ & $\begin{array}{l}\text { Política Publica. } \\
\text { Plano Nacional } \\
\text { de Educação. } \\
\text { PNE 2001-2010. } \\
\text { Implementação. } \\
\text { Avaliação e } \\
\text { Monitoramento }\end{array}$ & Dissertação & $\begin{array}{c}\text { Xavier } \\
\text { Carvalho de } \\
\text { Sousa Neto }\end{array}$ & UNB \\
\hline 2014 & $\begin{array}{l}\text { Governança e formação } \\
\text { de professores: a } \\
\text { presença do Banco } \\
\text { Mundial no programa } \\
\text { gestar }\end{array}$ & $\begin{array}{l}\text { Governança } \\
\text { educacional } \\
\text { global. Formação } \\
\text { de professores. } \\
\text { Gestar II. Banco } \\
\text { Mundial. }\end{array}$ & Dissertação & $\begin{array}{l}\text { Cleber } \\
\text { Sardinha } \\
\text { Ribeiro }\end{array}$ & UCB \\
\hline 2015 & $\begin{array}{l}\text { Melhores políticas } \\
\text { para melhores vidas: } \\
\text { um estudo crítico } \\
\text { das concepções que } \\
\text { embasam o Programme } \\
\text { for International Student } \\
\text { Assessment (Pisa) no } \\
\text { período 1997-2012 }\end{array}$ & $\begin{array}{l}\text { Pisa. OECD. } \\
\text { Avaliação. } \\
\text { Equidade. } \\
\text { Qualidade da } \\
\text { Educação. } \\
\text { Accountability }\end{array}$ & Tese & $\begin{array}{c}\text { Guilherme } \\
\text { AndolfattoLi- } \\
\text { banori }\end{array}$ & UFSC \\
\hline
\end{tabular}

Fonte: Elaboração das autoras.

Quanto à instituição de origem dessas pesquisas, a Universidade Católica de Brasília (UCB), a Universidade de São Paulo (USP), a Universidade Católica do Rio Grande do Sul (UCRS), a Universidade Estadual de Campinas (UEC) e a Universidade de Brasília (UNB) concentram o maior número de estudos sobre a governança educacional, tendo 2 pesquisas concluídas em cada uma dessas instituições, no período de 2012 
a 2014. Os demais estudos estão elencados na Universidade Federal de Goiás (UFG), na Universidade Federal de São Carlos (UFSC) e na Universidade Estadual do Rio de Janeiro (UERJ).

No tocante à região geográfica, as teses e dissertações concentram-se nas regiões Centro-Oeste e Sudeste, tendo cinco estudos concluídos em cada uma delas. Os demais são oriundos da região Sul do País. A análise das palavras-chave indica a preocupação das pesquisas em conhecer e explorar os impactos da globalização neoliberal sobre as políticas públicas educacionais, especialmente sobre o fenômeno da governança. Os principais elementos explorados nos estudos, de acordo com as ocorrências das palavras-chave e leitura dos resumos foram: educação; política de Estado; governança educacional; política educacional; avaliação; políticas públicas e reforma.

A pesquisa na pós-graduação da área de Educação sobre governança, apesar de ter seus primeiros registros em 2012, aprofundou-se especialmente a partir de 2014. O conceito de governança e sua relação com a educação ainda é muito recente, especialmente na literatura brasileira, conforme apontam as pesquisas encontradas. Nesse sentido, explorar o campo teórico sobre a governança da educação faz-se premente para o campo das políticas educacionais ante a reconfiguração da atuação do Estado por força do neoliberalismo e da globalização. $O$ fato de a maior parte da produção sobre governança ainda se encontrar em língua inglesa pode ser um dos fatores que esteja limitando a realização de mais pesquisas sobre o tema por pesquisadores brasileiros que estudam a gestão, a política e o financiamento da educação, mas essa hipótese precisa ser melhor investigada.

A análise dos resumos1 dos trabalhos da base BDTD e a leitura na íntegra do artigos da base SciELO, segundo a análise de conteúdo proposta por Bardin (2010), contribuíram para a construção de duas categorias de análise: política educacional $e$ reconfiguração do Estado. Os critérios para definição dessas categorias levaram em consideração o objetivo central de cada estudo e a ocorrência das palavras-chave. Portanto, as categorias descritas serão utilizadas para a análise das pesquisas das duas bases de dados em foco. a leitura completa dos artigos, teses e dissertações apontadas neste artigo. 


\section{A produção da base SciELO}

A produção acadêmica levantada na base SciELO permitiu verificar a complexidade do fenômeno da "governança", especialmente quando aplicado na área de educação. A governança é identificada como um produto natural da globalização e das ideologias neoliberais, que desperta grande interesse dos pesquisadores imbuídos no propósito de analisar a dinâmica do Estado e suas transformações políticas, econômicas e sociais em decorrência de suas novas relações com o mercado.

Algumas expressões presentes nos artigos, tais como constitucionalização neoliberal e fusão da regulação e emancipação (Dale, 2010), deslocamentos artificiais (Mateus, 2014), volátil e governabilidade (Amos, 2010), agenda globalmente estruturada para a educação (Dale, 2004), privatização e parcerias público-privadas (Robertson; Verger, 2012) e nova gestão pública (Newman; Clarke, 2012), demonstram a fragilidade das políticas públicas educacionais, como resultado da constante descentralização do papel do Estado. Destaca-se também que os estudos de Dale (2010) e Robertson (2013) trazem uma reflexão para o campo social e reforçam a importância da sociologia da educação e da ciência política, para melhor analisar o termo governança e seus impactos na sociedade e na educação.

As pesquisas encontradas foram analisadas com base nas categorias política educacional e reconfiguração do Estado, com o intuito de melhor compreender as discussões levantadas. Nota-se que essas categorias estão imbricadas, pois, inicialmente, os estudos procuram decifrar e contextualizar a política no campo educacional, e, consequentemente, conhecer e analisar a nova forma de atuação do Estado. Os discursos em tela se baseiam na auto-organização e nas parcerias (redes políticas que envolvem o setor público, privado e voluntário), cujas relações de poder se manifestam de diferentes formas (Ball, 2013).

Quanto à categoria política educacional, a maioria dos artigos destaca a existência de diferentes atores e instituições envolvidos no campo das políticas públicas de educação. As palavras de ordem descritas nesses estudos são reconfiguração e regulação, no sentido de propagar um projeto educacional global, comum e homogeneizado, que defende a sobrevivência do capitalismo (Amos, 2010; Dale, 2010; Robertson, 2013) e novas formas de colonização por meio das políticas educacionais. Para trabalhar o conceito de governança, os estudos descrevem dois instrumentos fundantes das reformas educacionais:a privatização e a globalização (Dale, 2004; Robertson; Verger; 2012). Verifica-se, contudo, que o conceito de governança ainda é muito polissêmico, o que dificulta sua análise e definição no campo educacional. No tocante à privatização, Robertson e Verger (2012) analisam as parcerias público-privadas em educação, cujo objetivo centra-se na reconstrução da 
educação pública para servir ao mercado. Os autores apontam que há uma distorção da educação como bem público e de responsabilidade do Estado, que passou a servir às necessidades do mercado.

A análise da categoria reconfiguração do Estado evidencia que a influência da globalização extrapola os limites do Estado, faz com que este recue no exercício do seu papele promova o avanço das relações de mercado. O estudo de Mateus (2014) exemplifica esse fenômeno ao abordar os atuais processos de formação docente, ancorados em projetos de reestruturação social, cultural e produtiva. A autora analisa a formação docente sob o prisma do Programa Institucional de Bolsa de Iniciação à Docência (Pibid), destacando a parceria entre as IES e a educação básica. A autora ressalta a presença da governança nessa complexa rede de parceria, que envolve outros atores oriundos especialmente do mercado, com a justificativa de flexibilizar e dinamizar a formação docente, tendo em vista à crescente demanda por professores com curso superior, a custos reduzidos. Nesse caso, a governança gera um grande impacto, não apenas na formação, cada vez mais híbrida e artificial, mas, principalmente, nas condições de trabalho docente e na qualidade da educação oferecida, que passam a ser mais precarizados.

Para dar conta da relação volátil entre Estado e sistema educacional, Amos (2010) usa o termo governabilidade e tece seu conceito dentro da concepção foucaultiana. Nessa perspectiva, a governabilidade vai além dos aspectos técnicos que definem a governança diante da intensa relação entre conhecimento e poder. Um olhar crítico permite identificar o binômio conhecimento/poder nos estudos em tela, uma vez que os conceitos e os efeitos da governança educacional apontam para a influência do mercado sobre o Estado, o que explica a nova forma de atuação deste último.

Conforme Dale (2010), a reconfiguração do Estado atribuída à mudança de governo para governança, tem como base a constitucionalidade neoliberal e se justifica em razão da fusão entre "regulação e emancipação". Há um apelo cada vez maior para uma avaliação quantitativa, com foco no produto e não necessariamente, no processo. Os estudos em tela tratam não somente do conceito "governança" e sua relação com a educação, mas principalmente, sobre suas implicações na nova forma de gestão vigente, com apelo às relações econômicas. Newman e Clarke (2012) também contribuem para uma reflexão sobre a política educacional e a reconfiguração do Estado ao tratarem dos novos arranjos políticos, próprios da governança, que aparece como algo "inovador", com o argumento de tornar a gestão das organizações (incluindo-se aqui, o Estado) mais livres e com maior autoridade gerencial. A avaliação, portanto, torna-se o principal instrumento de gestão do Estado, adotada na esfera educacional (Dale, 2004; 2010). 
A produção acadêmica da base SciELO, apesar de limitada em número de pesquisas, revela-se fundamental para compreender o enfoque regulador e coordenador do Estado. A riqueza teórico-metodológica da produção encontrada é facilmente percebida ao longo dos textos, que discutem a origem, o conceito e as implicações da governança para a área educacional e mantém vínculo estreito com os estudos da sociologia da educação.

\section{As pesquisas da BDTD}

As pesquisas registradas na BDTD revelaram o empirismo como base epistemológica. A maioria dos trabalhos busca compreender situações diversas vivenciadas pelos próprios pesquisadores, que procuram discutir o efeito prático do modelo de governança engendrado no contexto educacional. $O$ objeto de estudo desse campo emergente se volta, essencialmente, para as questões pertinentes à qualidade da educação, às relações público-privadas, à privatização, à formação e ao trabalho docente. Verificou-se uma opção unânime pela abordagem qualitativa, com algumas ilações quantitativas, e a maior parte das pesquisas optou pelo estudo de caso.

As dissertações e teses abordam, em sua maioria, a educação pública de nível básico. Dentre os estudos identificados, apenas a pesquisa de Santos (2012) analisa a governança educacional sob a perspectiva da educação superior privada. Vale ressaltar que todos os estudos fazem referência ao Banco Mundial, à OCDE e a outros atores transnacionais e nacionais não-estatais como precursores e disseminadores do modelo hegemônico de governança.

Com relação à categoria política educacional, os estudos evidenciaram o impacto da governança na formação e no trabalho docente, tendo como consequência imediata a perda qualidade da educação. Exemplos disso são os estudos sobre o Programa Gestar II no Distrito Federal (Ribeiro, 2014) e o Pacto pela Educação no Estado de Goiás (Araújo Júnior, 2013). Ambos questionam a interferência de atores não estatais na elaboração e disseminação desses projetos, com destaque para o Banco Mundial. Reforçam, ainda, que há uma limitação na visão crítica por parte dos professores sobre a influência de outros atores na política educacional. Araújo Júnior (2013) entende que projetos dessa natureza são mecanismos de governança criados estrategicamente pelos organismos internacionais. Como consequência, há a ampliação da privatização do público em função da acumulação flexível do capital, o que afeta, diretamente, o trabalho docente. 
Na educação superior privada, os efeitos das transformações na política educacional sobre o trabalho docente não são diferentes, como aponta Santos (2012). Esse estudo problematiza a governança a partir da formação de oligopólios educacionais, destacando a mercantilização do ensino superior privado e suas implicações nas condições de trabalho. A autora, ao analisar uma Instituição de Ensino Superior do Distrito Federal, pertencente a um dos maiores grupos educacionais do mundo, deixa claro que a formação de oligopólios intensifica o trabalho docente, restringe a autonomia desse profissional, e, consequentemente, compromete a qualidade da educação.

Os trabalhos de Leandro (2012) e Higueras (2014) colocam em evidência a fragilidade do sistema político no Brasil e na América Latina e destacam a centralidade da governança como panaceia das mazelas sociais, que tem na educação seu fio condutor. Destarte, há uma intensa redução no papel do Estado, que passa a atuar como regulador e avaliador das políticas educacionais. Conforme as pesquisas, os reflexos são imediatos no projeto educativo, a começar pela formação docente (Ribeiro, 2014; Araújo Júnior, 2013). Para Santos (2012) e Araújo Júnior (2013), é fundamental uma ressignificação da politicidade docente, para que este seja capaz de se organizar em torno de novas bandeiras e lutas e, assim, assegurar a autonomia, a valorização da profissão e melhores condições de trabalho.

Quanto à categoria reconfiguração do Estado, as análises identificam a atuação do Estado como regulador e coordenador das políticas públicas, com vistas a cumprir acordos econômicos e políticos. A construção de novas redes políticas constituídas por diversos atores, a criação de instrumentos de padronização do aprendizado, como o Programme For International Student Assessment(PISA), a incorporação de ações afirmativas e o incentivo ao ranqueamento das instituições de ensino são reflexos do modelo de boa governança, como evidenciam Higueras (2014), Libaroni (2015), Tripodi (2014), Sousa Neto (2014) e Lima e Silva (2013).

Nesse cenário, identifica-se uma profunda mudança no papel do Estado, que é reflexo das principais implicações da política neoliberal (Santos, 2012; Higueras, 2014; Tripodi, 2014). Com a limitação e a descentralização das funções do Estado, abrem-se novos espaços para uma reforma gerencial e o Estado se afasta do papel de provedor dos direitos sociais para os cidadãos para garantir a execução dos acordos firmados com o mercado interno e externo. As pesquisas analisadas apontam que o atual modelo de governança hegemônico sofre ingerência de uma gama de atores, instituições e ideologias distintas que promovem as relações de mercado em detrimento do bemestar social. 


\section{Conclusão}

O termo governança é concebido e empregado de modo diferenciado na literatura educacional brasileira. Os usos referentes à governança como Estado mínimo, boa governança e redes de auto-organização (Rhodes, 1996) tiveram maior recorrência nas pesquisas analisadas, uma vez que suas concepções relacionam-se, respectivamente, à intervenção pública para cooperação com a atuação do mercado no fornecimento de serviços públicos; a novas formas de governo que devem abrir portas para o setor privado, cooperando com o desenvolvimento do capitalismo; e à presença de outros atores na gestão pública, com serviços prestados em forma de barganhas entre governo, setor privado e sociedade civil organizada.

A análise das pesquisas aponta que o debate sobre a governança educacional no Brasil precisa ganhar mais espaço no campo das pesquisas em educação, principalmente na área da política, da gestão, do financiamento e da avaliação da educação. A produção dos pesquisadores brasileiros indica ser urgente ampliar o conhecimento da academia sobre o tema, que, entretanto, precisa ser investigado a partir de perspectivas críticas e emancipatórias. É preciso compreender a complexidade da rede e identificar os nós mais fortes para que novas alternativas possam ser propostas e relações mais humanizadas possam ser construídas e incluídas nesse imbricado campo da rede de governança das políticas de educação no país.

"Quem governa a educação no Brasil? Que tipo de cidadania é promovida pelo atual modelo de governança educacional hegemônico? Quais são os interesses, contradições e desafios no campo da governança da política educacional brasileira contemporânea?" (Guimarães-losif, 2012, p.17). O estudo da governança educacional e de suas redes pode nos ajudar a encontrar respostas para questionamentos tão imperiosos. Portanto, é mister "investigar a trama de governança que está sendo estabelecida, o nível de influência (aspecto político, técnico ou ambos) e os padrões de regularidades possíveis de se encontrar" (Hoyler et al., 2014, p. 98). A criação de uma agenda de pesquisa acerca do tema auxiliará na elucidação das motivações, interesses, prioridades e racionalidades abarcadas em cada uma das parcerias firmadas, bem como no acesso aos recursos políticos e financeiros empregados pela rede de atores nos arranjos estabelecidos e na sistematização das principais conexões. 


\section{Referências}

AMOS, Karen. Governance and Governmentality: Relation and Relevance of Two Prominent

Social Scientific Concepts for Comparative Education. Educação e Pesquisa, São Paulo, v. 36, n. especial, p. 23-38, 2010.

ARAÚJO JÚNIOR, João Ferreira de. O trabalhador da educação e a acumulação flexível do capital: um estudo do posicionamento do Sintego frente à política educacional de Goiás. 2013. 128f. Dissertação (Mestrado em Educação) Programa de Pós-graduação em Educação, Universidade Federal de Goiás, 2013.

BALL, Stephen J. Novos Estados, nova governança e nova política educacional. In: APPLE, Michael; BALL, Stephen J.; GANDIN, Luís Armando (Orgs.), Sociologia da educação: análise internacional. Porto Alegre: Penso, 2013. p. 177-189.

BARDIN, Laurence. Análise de conteúdo. Trad. Luís Antero Reto e Augusto Pinheiro. Lisboa, Portugal: Edições 70, 2010.

BATISTÃO, Sandra Paula da Silva. Educação inclusiva ou educação para todos? contribuições da teoria histórico-cultural para uma análise crítica da realidade escolar. 2013. 147f. Dissertação (Mestrado em Ciências) -Programa de Pósgraduação em Mudança Social e Participação Política, Universidade de São Paulo, 2013.

BEVIR, Mark. Governança Democrática: uma Genealogia. Revista de Sociologia e Política, Curitiba, v. 19, n. 39, p. 103-114, jun., 2011.

BRASIL. Congresso Nacional. Lei no 9.394 de 1996, de 20 de dezembro de 1996. Estabelece as diretrizes e Bases da Educação Nacional. Brasília: Senado Federal, 1996.

. Presidência da República. Constituição da República Federativa do Brasil, de 05 de outubro de 1988. Brasília: Senado Federal, 1988.

. Presidência da República. Plano Diretor da Reforma do Aparelho do Estado. Brasília, 1995. Brasília: Presidência da República, 1995.

DALE, Roger. A sociologia da educação e o estado após a globalização. Educação \& Sociedade, Campinas, v. 31, n. 113, p. 1099-1120, out./dez., 2010. 
. Globalização e educação: demonstrando a existência de uma "cultura educacional mundial comum" ou localizando uma "agenda globalmente estruturada para a educação"? Educação \& Sociedade, Campinas, v. 25, n. 87, p. 423-460, maio./ ago., 2004.

. Globalização e reavaliação da governação educacional. Um caso de ectopia sociológica. In: TEODORO, Antonio; TORRES, Carlos Alberto (Orgs). Educação crítica \& utopia: perspectivas para o século XXI. São Paulo: Cortez, 2006. p. 60-80.

ETGES, Adelmo Germano. A pessoa do gestor e do educador leigo como estimuladores da proposta educativa Marista no RS: do empenho original do fundador, Marcelino Champagnat, aos desafios do século XXI. 2014.198f. Dissertação (Mestrado em Educação) - Programa de Pós-graduação em Educação, Universidade Católica do Rio Grande do Sul, 2014.

GUIMARÃES-IOSIF, Ranilce. Introdução. In: GUIMARÃES-IOSIF, Ranilce (Org.), Política e governança educacional: disputas, contradições e desafios diante da cidadania. Brasília, DF: Universa: Líber Livro, p. 17-23.

HIGUERAS, Jorge Luis Inzunza. A reforma educacional chilena na América Latina (1990-2000): circulação e regulação de políticas através do conhecimento. 2014. 306f. Tese (Doutorado em Educação) - Programa de Pós-graduação em Educação, Universidade Estadual de Campinas, 2014.

HOYLER, Telma; BURGO, Fernando; BRESLER, Ricardo; PAULICS, Veronika. Governança ajuda ou atrapalha? Reflexões sobre a gestão educacional local. Revista Interdisciplinar de Gestão Social, v. 3, n. 2 p. 81-102, maio/ago., 2014.

JESSOP, Bob. Política Social, Estado e "Sociedade". SER social, Brasília, v.15, n. 33, p. 261-284, jul./dez., 2013.

The Changing Governance of Welfare: Recent Trends in its Primary Functions, Scale, and Modes of Coordination. Social Policy \& Administration, v. 33, n. 4., p. 348-359, dec.,1999.

LAIA, Maria da Glória dos Santos. O Instituto Federal de Educação, Ciência e Tecnologia (Instituto Federal) como nova institucionalidade na educação Profissional e Tecnológica (EPT): uma análise na perspectiva de rede de política pública. 2013. 112f. Dissertação (Mestrado em Educação) - Programa de Pós-graduação em Educação, Universidade de Brasília, 2013.

LEANDRO, Sonia de Pontes. Ouvidoria da educação: a construção de espaços 
de mediação de conflitos no cotidiano escolar de Nova Iguaçu. 2012. 174f. Dissertação (Mestrado em Educação) - Programa de Pós-graduação em Educação, Universidade do Estado do Rio de Janeiro, 2012.

LIBANORI, Guilherme Andolfatto. Melhores políticas para melhores vidas: um estudo crítico das concepções que embasam o Programme for International Student Assessment (Pisa) no período 1997-2012. 2015. 161f. Tese (Doutorado em Educação) Programa de Pós-graduação em Educação, Universidade Federal de São Carlos, 2015.

LIMA, Jorge Ávila de. Redes na educação: questões políticas e conceptuais. Revista Portuguesa de Educação, Lisboa, v. 20, n. 2, p.151-181, 2007.

LIMA E SILVA, Isabel Cristina de Andrade. Política nacional de educação infantil: a participação de atores não estatais na elaboração da política pública. 2013. 265f. Tese (doutorado em Educação) - Programa de Pós-graduação em Educação, Universidade Estadual de Campinas, 2013.

MATEUS, Elaine Fernandes. Um esboço crítico sobre "parceria" na formação de professores. Educação em Revista, Belo Horizonte, v. 30, n. 03, p. 355-384, jul./ set., 2014.

NEWMAN, Janet; CLARKE, John. Gerencialismo. Educação Real, Porto Alegre, v. 37, n. 2, p. 353-381, maio/ago., 2012.

OECD.ORGANIZATIONFORECONOMICCO-OPERATIONANDDEVELOPMENT. Governance in Transition: public management reforms in OECD countries. Paris: OECD, 1995.

REIS, Isaura. Governança e Regulação da Educação - perspectivas e conceitos. Educação, Sociedade \& Culturas, n. 39, p. 101-118, 2013.

RHODES, Roderick Arthur William. The new governance: governing without government. Political Studies, v. 44, p. 652-667, 1996.

RIBEIRO, Cleber Sardinha. Governança e formação de professores: a presença do banco mundial no programa gestar. 2014. 158f. Dissertação (Mestrado em Educação) - Programa de Pós-graduação em Educação, Universidade Católica de Brasília, 2014.

ROBERTSON, Susan. As implicações em justiça social da privatização nos modelos de governança da educação: um relato relacional. Educação \& Sociedade, Campinas, v. 34, n. 124, p. 679-703, jul.-set. 2013.

ROBERTSON, Susan; VERGER, Antoni. A origem das parcerias público-privada na 
governança global da educação. Educação \& Sociedade, Campinas, v. 33, n. 121, p. 1133-1156, out.-dez. 2012.

ROSENAU, James N. Governança, Ordem e Transformação na Politica Mundial. In: ROSENAU, James N.; CZEMPIEL, Ernst-Otto, Governança sem governo: ordem e transformação na política mundial. Trad. Sérgio Bath. Brasília: Editora Unb e São Paulo: Imprensa Oficial do Estado, 2000. p. 11-46.

SANTOS, Aline Veiga dos. A governança da educação superior privada: sobreimplicações da formação dos oligopólios no trabalho docente. 2012. $161 \mathrm{f}$. Dissertação (Mestrado em Educação) - Programa de Pós-graduação em Educação, Universidade Católica de Brasília, 2012.

SANTOS, Boaventura de Sousa. A gramática do tempo:para uma nova cultura política. 3. ed. São Paulo: Cortez, 2010.

SCHMITZ, Taís. Reconfiguração da gestão da educação: um estudo de caso na segunda Coordenadoria Regional de Educação de São Leopoldo/RS. 2013. $279 f$. Tese (Doutorado em Educação) - Programa de Pós-graduação em Educação, Universidade Católica do Rio Grande do Sul, 2013.

SOUSA NETO, Xavier Carvalho de. Plano Nacional de Educação - PNE 2001-2010: análise de fatores que influenciaram sua implementação no âmbito da união. 2014. 365f. Dissertação (Mestrado em Educação) - Programa de Pós-graduação em Educação, Universidade de Brasília, 2014.

STOKER, Gerry. Governance as Theory: Five Propositions. International Social Science Journal, v. 50, n. 1, p. 17-28, 1998.

TAVARES, Sérgio Marcus Nogueira. Governança no ensino superior privado. In: COLOMBO, Sônia Simões (Org.). Desafios da gestão universitária contemporânea. Porto Alegre: Artmed, 2011. p. 175-190.

- Governança em universidades confessionais no Brasil: modelo em construção. Educação \& Linguagem, São Bernardo do Campo, v. 12. n. 19, p. 219238, jan./jun., 2009.

TRIPODI, Maria do Rosário Figueiredo. A instituição da agenda contratual na educação mineira: arquitetura de uma reforma. 2014. 313f. Tese (Doutorado em Educação) - Programa de Pós-graduação em Educação, Universidade de São Paulo, 2014.

WORLD BANK. Governance and Development. Washington, D. C.: World Bank, 1992. 
Recebido em 13 de fevereiro de 2016

Aprovado em 01 de março de 2017.

Aline Veiga dos santos é Doutoranda em Educação pela Universidade Católica de Brasília, com bolsa de estudo ofertada pelo governo do Canadá, programa ELAP 2014. Integrante do projeto de pesquisa financiado pelo CNPa sobre o Programa Ciência Sem Fronteiras.Email: aveigadossantos@gmail.com

Isabela Cristina Marins Braga é Doutoranda em Educação pela Universidade Católica de Brasília. Administradora e professora do ensino superior. Integrante do projeto de pesquisa financiado pelo CNPq sobre o Programa Ciência Sem Fronteiras. Email: halleyhotelunai@gmail.com

Ranilce Mascarenhas Guimarães-losif é Professora do Programa de Pós-graduação em Educação da Universidade Católica de Brasília - UCB e Adjunct Assistant Professor with the Department of Educational Policy Studies and Research Fellow with the Centre for Global Citizenship Education \& Research (CGCER), University of Alberta, Canadá.

Email: ranilceguimaraes@yahoo.com.br 